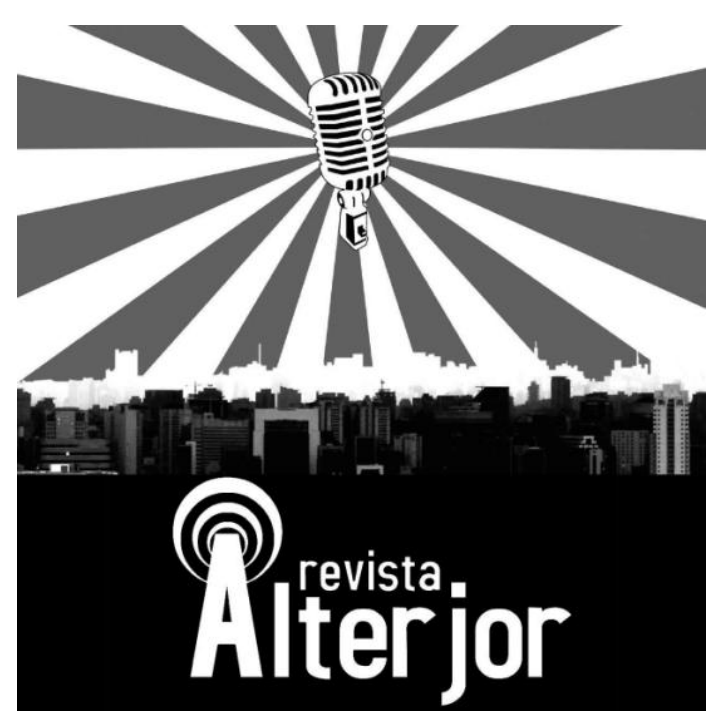

\title{
A PRODUÇÃO DE SENTIDOS SOBRE O VALE DO JEQUITINHONHA PELA TV PRAÇA: UM GESTO DE OLHAR PARA A COMUNICAÇÃO COMUNITÁRIA
}

\author{
Ivanise Hilbig de Andrade ${ }^{1}$ \\ Elainy Carmona Pereira ${ }^{2}$
}

RESUMO: A pesquisa investiga como os agentes produtores de conteúdo comunitário da TV Praça, uma produção audiovisual realizada por jovens participantes da Assessoria de Comunicação Colaborativa Itaobim 50 anos, projeto Polo Jequitinhonha (UFMG), constroem sentidos sobre o Vale do Jequitinhonha. São analisadas duas edições da TV Praça e suas condições de produção de sentidos, utilizando-se de um aparato teórico-metodológico da Análise de Discurso, por uma perspectiva da sóciossemiótica. Assim, é levado em consideração as condições de produção e o potencial político da comunicação comunitária, realizada por grupos vistos como subalternos na sociedade. A partir dessas discussões, é possível concluir que quando esses grupos se tornam produtores de conteúdo, construindo sentidos sobre si mesmos, eles conseguem ressignificar estereótipos muitas vezes criados pelos meios de comunicação tradicionais.

PAlAVRAS-CHAVE: Comunicação Comunitária. Audiovisual Comunitário. Análise de discurso. Vale do Jequitinhonha. TV Praça.

\begin{abstract}
The research investigates how the producers of community content of TV Praça, construct meanings about the Jequitinhonha Valley. Two editions of TV Praça, a community audiovisual production and linked to extension projects of the Federal University of Minas Gerais, are analyzed, thus, the discourse analysis is used. Thus, the conditions of production and the political potential of community communication are taken into account by groups seen as subalterns in society. From these discussions, it is possible to conclude that when these marginalized groups become content producers, creating content and senses about themselves, they are able to escape from stereotypes imposed on them by the traditional media, causing an exaltation of their hometown.
\end{abstract}

KEYWORDS: Community communication's. Community audio-visual. Speech analysis. Vale do Jequitinhonha. TV Praça.

\footnotetext{
${ }^{1}$ Jornalista, Mestre em Estudos de Linguagens (UFMS) e Doutora em Comunicação e Cultura Contemporâneas (UFBA). Docente da Faculdade de Comunicação da UFBA. Orientadora da pesquisa. Contato: ivaniseha@gmail.com

2 Jornalista graduada pela Universidade Federal de Uberlândia. Contato: carmonaelainy @ gmail.com
}

Revista ALTERJOR

Grupo de Estudos Alterjor:Jornalismo Popular e Alternativo (ECA-USP)

Ano 10 Volume 02 Edição $22 \quad$ Julho-Dezembro de 2020

Avenida Professor Lúcio Martins Rodrig̉ues, 443, Cidade Universitária, São Paulo, CEP: 05508-020 


\section{Introdução}

O Vale do Jequitinhonha é uma mesorregião mineira, localizada no nordeste do estado e subdivida em três partes: alto, médio e baixo vales. Carregando o nome do principal rio que o corta, a ocupação do Jequitinhonha ocorreu de maneira bastante conflituosa, mesclando povos indígenas, quilombolas, europeus e garimpeiros, que se instalaram na região em busca de ouro e pedras preciosas. Tal movimento de ocupação, fortemente marcado pela miscigenação entre europeus, indígenas e negros escravizados, criou uma grande diversidade de costumes que se evidencia principalmente nas manifestações culturais e religiosas. Apesar dos conflitos, a presença dos povos indígenas e dos quilombolas fizeram com que a identidade desses povos se construísse a partir dessas relações, que se explicitam nas manifestações artísticas e culturais da região. Segundo Soares (2000), a arte se mostra presente como traço fundamental da identidade do povo do Jequitinhonha a partir dessa herança indígena e africana.

A busca pela riqueza na região em meados do século XVII aumentou o fluxo migratório, consequentemente, as pessoas que se instalavam em volta do rio desenvolveram e fortaleceram a agricultura no local. Porém, a partir do momento em que os recursos naturais começaram a se extinguir, o fluxo migratório se inverte e esse movimento perdura até hoje, levando a população para grandes centros em busca de trabalho ou estudo.

Esse fluxo, aliado aos baixos índices de desenvolvimento humano históricos da região, constrói a maioria dos discursos que circula sobre o Jequitinhonha nos meios de comunicação considerados tradicionais. Em geral, reproduzem padrões de pautas ligadas à pobreza, drogas, exploração sexual de crianças e adolescentes e produção cultural, criando e reforçando estereótipos sobre o local (JARDIM, 1998). As angulações são parecidas e reduzem o debate, como aponta o pesquisador Caio Paranhos (2015), que analisou notícias sobre o Vale do Jequitinhonha, publicadas entre 2008 e 2013 na edição impressa do Jornal Estado de Minas. Paranhos concluiu que "a pobreza aparece em contraponto a uma riqueza cultural; mas a cultura adquire um espaço relevante no jornal, sendo, na maioria das vezes exaltada por ele" (PARANHOS, 2015, p. 63). 


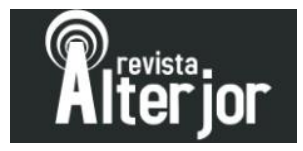

Em termos de jornalismo local, a região já contou com alguns jornais impressos, que se dividiam entre uma gestão independente e uma ligação com instituições religiosas. Hoje, porém, segundo dados do Atlas da Notícia ${ }^{3}$ (2019), a maioria das cidades não tem nenhum veículo de comunicação e algumas contam com um ou dois. Com relação ao conteúdo, uma breve observação aponta que nem sempre existe uma cobertura das notícias locais ou que problematize questões históricas.

Dentro desse cenário e com o objetivo de fomentar o desenvolvimento regional, a Universidade Federal de Minas Gerais, por meio da articulação de diversas unidades acadêmicas, criou, na década de 1990, o programa Polo Jequitinhonha, que está em funcionamento até hoje ${ }^{4}$. O programa implementou seu núcleo de Comunicação em 2003 e, desde então, tem desenvolvido iniciativas em cidades do Vale do Jequitinhonha, especialmente voltadas para a formação de jovens nas áreas de comunicação e produção audiovisual.

Dentre os projetos realizados pelo núcleo está a Assessoria de Comunicação Colaborativa (ACC) Itaobim $50 \operatorname{anos}^{5}$, que, em 2012, realizou oficinas na cidade de Itaobim (MG), localizada à 620 quilômetros da capital mineira. Ao longo daquele ano, jovens da cidade receberam formação e foram orientados para realizarem a divulgação e cobertura jornalística do calendário comemorativo do cinquentenário de emancipação da cidade. À época, a Assessoria de Comunicação Colaborativa Itaobim 50 anos era composta por cerca de 20 jovens divididos em quatro núcleos para produções distintas: Audiovisual, Criação Visual, Rádio e Web/Impresso. Os núcleos eram acompanhados por estudantes da Universidade Federal de Minas Gerais, bolsistas do Polo Jequitinhonha, e por jornalistas profissionais. Os tutores eram responsáveis por ensinar

\footnotetext{
${ }^{3}$ O Atlas da notícia é uma iniciativa que mapeia os veículos de comunicação ativos no país, disponível em: <https://www.atlas.jor.br/> Acesso: 21 de novembro de 2019.

${ }^{4}$ Conforme informações do site do programa, o Polo Jequitinhonha executa atividades em sete áreas de atuação: saúde, educação, comunicação e cultura, meio ambiente, direitos humanos, desenvolvimento regional e geração de renda. https://www.ufmg.br/polojequitinhonha/

${ }^{5}$ Parceria entre a Prefeitura Municipal de Itaobim, Pró Reitoria de Extensão da UFMG, Programa Polo de Integração da UFMG no Vale do Jequitinhonha e a organização Associação Imagem Comunitária (AIC), que já atuava na região desde 2007 por meio do projeto "Juventudes do Jequi”.
} 


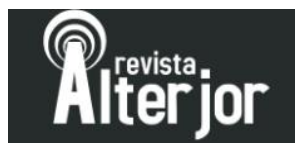

as técnicas e acompanhar a produção dos núcleos, mas os jovens tinham autonomia para propor pautas e produzir os conteúdos.

O núcleo de audiovisual da ACC Itaobim 50 anos, entre outras produções, desenvolveu ao longo de 2012 a "TV Praça", uma TV Comunitária de rua exibida quinzenalmente na praça principal de Itaobim. A produção conta com mais de 10 edições, que retratam o Vale do Jequitinhonha a partir da mescla entre o ponto de vista dos jovens realizadores e dos moradores.

Diante do exposto, esse artigo analisa como os agentes produtores de conteúdo comunitário da "TV Praça" constroem sentidos sobre o Vale do Jequitinhonha. Para tanto, foram analisadas duas edições da TV Praça, utilizando metodologia de análise inspirada na sóciossemiótica proposta por Eliseo Verón (2004). Também serviram de base teórica para o trabalho os conceitos de Comunicação Comunitária (PERUZZO, 2002; 2006; 2009) e de Audiovisual Comunitário (ALVARENGA, 2010). Além disso, foram realizadas duas entrevistas: uma com o jornalista e tutor do núcleo de audiovisual à época e uma com uma (ex)integrante do núcleo. Eles recontam a história da Assessoria de Comunicação Colaborativa Itaobim 50 anos a partir da experiência dos agentes envolvidos. $\mathrm{O}$ artigo está organizado em uma introdução/problematização, um tópico teórico sobre comunicação comunitária e a TV Praça, um tópico de explicitação da metodologia e tópicos e subtópicos de análise, além das considerações finais.

\section{TV Praça: uma TV Comunitária de Rua}

A TV Praça, conforme informado anteriormente, foi uma das ações realizadas pela Assessoria de Comunicação Colaborativa (ACC) Itaobim 50 anos, mobilizando jovens a pensar e realizar uma produção audiovisual dentro de uma perspectiva de comunicação comunitária. Segundo Peruzzo (2009), esse tipo de comunicação ganha força no Brasil durante a ditadura militar, quando grupos privados de liberdade de expressão se organizam para mudar a realidade da época. Ao fim do período ditatorial, muitos desses grupos são extintos, mas no começo do século XXI graças, entre outros fatores, à democratização de tecnologias de informação e comunicação, novos movimentos ressurgem e se manifestam. Surgem, então, muitas experiências ligadas a 


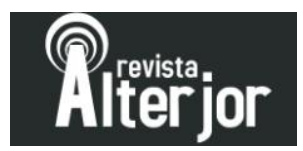

movimentos sociais, associações comunitárias e de vários outros tipos de organizações não governamentais, segmentos comunitários autônomos (infanto-juvenil, estudantil etc.), projetos de extensão (e de outros tipos) de universidades, iniciativas de rádioescola que muitas vezes extrapolam o espaço escolar e estabelecem elos com a comunidade local e assim por diante (PERUZZO, 2009 p. 134).

A comunicação comunitária também é chamada de alternativa, horizontal, popular, dialógica e educativa (KOSLINSKI, 2016), dependendo do contexto social em que está inserida. Não se trata apenas de um tipo de mídia, mas sim de um processo de comunicação que emerge de grupos populares subalternos e que apresentam suas singularidades a partir de ângulos diferentes dos vistos nas mídias tradicionais. Peruzzo (2009, p. 132) defende que esse tipo de produção representa uma "contracomunicação", que além de exercitar a liberdade de expressão, oferece conteúdos diferenciados e que servem de instrumento de conscientização.

A TV comunitária de rua, por sua vez, é caracterizada pela produção audiovisual com participação popular e que é transmitida em espaços públicos, destinados à recepção coletiva. Vale ressaltar que essas iniciativas não são canais de televisão, mas podem se utilizar de suportes televisivos, geralmente sendo veiculados em canais educativos tradicionais (PERUZZO, 2002). Além disso, o processo de produção desses projetos pode estar relacionado a alguma entidade, como ONGs, igrejas, ou universidades, que sedem pessoas para tutorar a produção. A participação popular é o objetivo principal, uma vez que a TV comunitária que segue os moldes da TV de Rua possui propósitos educativos e culturais e suas produções são realizadas utilizando o audiovisual comunitário.

Por sua vez, o audiovisual comunitário surge da concepção do "vídeo popular", que nasce embebido do espírito vanguardista da década de 1960, na Europa, e que serve como instrumento de poder para que o público possa se manifestar sobre diversos assuntos. "A ideia central era que a câmera deveria estar nas mãos das pessoas para que elas próprias pudessem tomar as suas imagens do mundo" (ALVARENGA, 2010, p. 91). O movimento defendia a participação direta das pessoas na produção de imagens e, para Clarice Alvarenga (2010), esse processo não se dá apenas pela evolução 


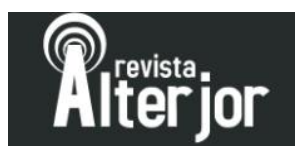

tecnológica que possibilita maior acesso aos instrumentos de produção, mas também por decisões políticas dos produtores de vídeos ligados a movimentos sociais.

Na década de 1990, o movimento brasileiro de vídeo popular passa por uma reestruturação na sua forma de produzir e organizações e projetos começam a ministrar oficinas técnicas nas comunidades. Com isso, o audiovisual comunitário ascende e passa a promover o direito à comunicação e à liberdade de expressão, criando possibilidades de interlocução. Assim, esse tipo de produção audiovisual consegue viabilizar uma pluralidade de representações sociais, transformando a dinâmica dessas e mudando as perspectivas e discursos que se fazem notáveis publicamente (MENDONÇA, 2010).

De acordo com o jornalista Israel Campos ${ }^{6}$, tutor responsável pelo núcleo de audiovisual da ACC Itaobim 50 anos à época, responsável por coordenar as atividades da TV Praça, a seleção dos jovens participantes ocorreu em 2011, seguindo critérios socioeconômicos e disponibilidade para trabalhar em coletivo. O grupo de 20 jovens idealizou e produziu os conteúdos da TV Praça, cuja programação era dividida em três quadros: "Doc Jequil, quadro principal da TV e composto pelos documentários produzidos pelos jovens; "Curta legal”, quadro de curtas metragens relacionadas à temática do documentário principal; e o quadro "Boca no Trombone", que trazia a opinião da população em enquetes sobre o tema principal da edição.

A TV era exibida quinzenalmente na parede do coreto da praça principal da cidade. Os vídeos produzidos e exibidos permitiam a participação da população por ser transmitida em um local aberto destinado à recepção coletiva, gerando, assim, uma interação entre os jovens produtores da Assessoria de Comunicação Colaborativa e o público. A TV Praça pode ser considerada uma TV Comunitária de Rua na medida em que promove essa interação e tem propósitos educativos e culturais, atuando como "facilitador do processo de tomada de consciência e mobilização de segmentos sociais excluídos", conforme Peruzzo (2002, p. 11). Outras características da TV de rua incluem: exibição itinerante, recepção coletiva, participação popular nas várias etapas do processo de produção, ligação com movimentos e entidades sociais, além de ter

\footnotetext{
${ }^{6}$ Em entrevista realizada em 2018 para a elaboração desta pesquisa. 


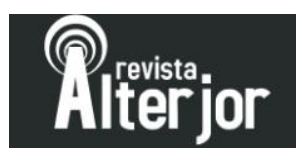

como objetivo democratizar o acesso e a produção de conteúdo audiovisual (PERUZZO, 2002).

De maneira geral, a produção realizada na TV Praça contribuiu também para a inserção social da população em processos de vínculo local e identitário. A ideia de inserção e contribuição para elevação da autoestima converge com a proposta do projeto no qual a TV Praça fazia parte. De acordo com o jornalista Israel Campos, o saldo dessa prática pode ser visto na forma com que os participantes se comportavam.

Percebi que mais no final do projeto eu via os jovens com autoestima elevada, a galera bem entrosada, participativa. Eu acho que essas experiências possibilitaram que os jovens tivessem contato com a cultura local de maneira mais crítica, mais respeitosa, de compreender que nem sempre o que vem de fora era melhor, que era algo que a gente sempre propunha. (CAMPOS, 2018)

Nessa mesma perspectiva, Anna Beatriz Sicupira ${ }^{7}$, jovem que participou da construção da TV Praça à época, avalia que o mais importante da experiência foi o "aprendizado que ficou, não só pra mim, mas em todo mundo que passou por lá". "Depois disso, eu passei a ficar completamente apaixonada pela minha cidade, a ver beleza onde as pessoas falam que só tem seca, onde falam que é o vale da pobreza, mas pra mim não é, eu passei a ver riqueza. (SICUPIRA, 2018).

\section{A produção de sentidos da Comunicação Comunitária: metodologia de análise}

De acordo com o semioticista Eliseo Verón (2004), uma análise sociossemiótica de produtos comunicacionais deve considerar sua complexidade em termos de elementos internos de sua gramática de construção de sentidos, bem como elementos externos, como o contexto em que foi produzido. Sendo assim, a análise proposta e realizada nesta pesquisa, pelas suas especificidades, demandou a construção de um aparato metodológico que incluísse um olhar para as condições de produção do discurso e também para os sentidos que emergem desse discurso produzido pelos jovens participantes da TV Praça sobre o Vale do Jequitinhonha. Assim, a análise operou em duas frentes, não necessariamente independentes, mas interligadas e realizadas

\footnotetext{
${ }^{7}$ Em entrevista realizada em 2018 para a elaboração desta pesquisa. 


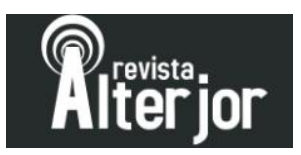

conjuntamente. Buscou-se compreender de forma qualitativa como os agentes produtores de conteúdo no contexto da comunicação comunitária produzem sentidos sobre o Vale do Jequitinhonha.

As edições da TV Praça analisadas foram exibidas quinzenalmente na praça Afonso Martins, na cidade de Itaobim (MG), entre os meses de abril e novembro de 2012. Após as exibições, os vídeos foram hospedados no youtube, no canal oficial da Assessoria de Comunicação Itaobim 50 anos. Algumas das exibições não foram hospedadas na plataforma, dessa forma, de um total de 10 vídeos armazenados, foram selecionados como corpus de análise desta pesquisa duas edições completas da TV Praça - a sexta e a nona edições ${ }^{8}$.

Para analisar o conteúdo selecionado, utilizou-se a Análise de Discurso, em especial a noção de "dispositivo de enunciação" (VERÓN, 2004), buscando compreender o processo de produção de sentidos sobre o Vale do Jequitinhonha. O dispositivo de enunciação explica as modalidades do dizer a partir das relações estabelecidas entre enunciadores e coenunciadores. O dispositivo de enunciação comporta, assim, "a imagem de quem fala (...); a imagem daquele a quem o discurso é endereçado (...); a relação entre enunciador e coenunciador" (VERÓN, 2004, p. 218).

A análise de discurso possibilitou um olhar mais amplo para a complexidade do objeto analisado, levando em consideração os textos verbais, não verbais e as condições de produção, algo extremamente importante considerando uma TV comunitária de rua, produzida em uma região marginalizada. Diante disso, as categorias análise utilizadas para compreender a completude das edições da TV Praça foram: a) Planos b) Cenários c) Enquadramentos d) Elementos gráficos e) Movimentos de câmera f) Trilhas sonoras g) Fontes entrevistadas h) Falas dos entrevistados. As fontes de informações são consideradas nesta pesquisa como figuras discursivas, construídas no e pelo discurso a partir das posições sociais que ocupam no momento em que assumem sua posição enquanto fonte.

\footnotetext{
${ }^{8}$ Levando em consideração que uma das autoras dessa pesquisa integrou o núcleo de audiovisual da Assessoria de Comunicação Colaborativa Itaobim 50 anos à época, sendo também uma das agentes produtoras de conteúdo, o principal critério para a escolha do corpus foi o distanciamento pessoal. As duas edições selecionadas não contaram com a participação da pesquisadora em sua produção.
} 


\section{As condições de produção do discurso da TV Praça}

Eliseo Verón (2004) explica que o processo de produção de sentidos ocorre entre dois polos: a produção e o reconhecimento, cada um com suas gramáticas de funcionamento específicas. Entre esses polos, há a circulação, que depende do suporte tecnológico, do funcionamento da sociedade e da dimensão histórica (VERÓN, 2004). Assim, um primeiro olhar da análise volta-se para o contexto social, histórico e cultural da produção discursiva da TV Praça. Ou seja, inicialmente analisou-se o processo de produção e a forma com que ela constrói sentidos. Verón defende que "para que algo seja designado como condição de produção de um discurso ou de um tipo de discurso, é preciso que tenha deixado rastros no discurso" (VERÓN, 2004, p. 52). Para Orlandi (2005, p. 30), as condições de produção "compreendem fundamentalmente os sujeitos e a situação" e considera como condição o contexto imediato que a produção está inserida, incluindo as questões sociais, históricas e ideológicas.

A TV Praça, objeto analisado nesta pesquisa, é uma produção comunitária em que os jovens moradores da cidade de Itaobim produziam conteúdo audiovisual sobre a cidade e o Vale do Jequitinhonha a partir de um contexto social e de forma amadora. Essa avaliação se faz muito importante para que o produto seja analisado discursivamente, como defendido por Marcia Benetti:

O fato do discurso ser construído de forma intersubjetiva exige compreendê-lo como histórico e subordinado aos enquadramentos sociais e culturais. Se o vemos desse modo, necessariamente somos obrigados a abandonar outra visão ingênua, a que o discurso poderia ser analisado sem considerar o contexto de produção de sentidos (BENETTI, 2007, p. 108-109)

Assim, buscou-se compreender a rotina produtiva que resultou nas edições da TV Praça, e que permitem a sua existência enquanto materialidade discursiva. A TV Praça foi produzida pelo núcleo de audiovisual da Assessoria de Comunicação Colaborativa Itaobim 50 anos. Cerca de cinco jovens eram tutorados por um jornalista que usava dinâmicas e oficinas para ensinar o conteúdo técnico. Israel Campos, tutor da 
TV Praça na época, explicou como aconteciam essas dinâmicas na entrevista concedida para elaboração desta pesquisa:

Pensando por exemplo o jogo, que eu queria passar conceitos para pessoas que eram leigas no assunto eu fazia aquelas brincadeiras. Por exemplo: 'fotografe o objeto sem mostrar onde ele está' e fotografar outro objeto mostrando um detalhe dele, mas sem mostrar onde ele está. Ou fotografar um objeto mostrando onde ele está, então colocando as questões assim, da forma que deve ser seguido, de repente fotografar um objeto mostrando onde ele está, automaticamente vocês produziam imagens de plano fechado e plano aberto. (CAMPOS, 2018)

Os materiais produzidos nessas atividades eram sempre reutilizados nas exibições da TV, dessa forma, as condições de produção ficam perceptíveis no produto final. Outra questão é a evolução dos jovens participantes em relação à técnica. No decorrer dos meses, os participantes dominavam melhor os equipamentos utilizados, os métodos de captação de áudio e vídeo e a edição final do produto. Essa diferença fica clara na fala de Anna Beatriz Sicupira, ex-integrante do núcleo de audiovisual da Assessoria de Comunicação Colaborativa Itaobim 50 anos.

Lembro que a gente estava aprendendo a editar e uma vez aceleramos o vídeo inteiro, depois aprendemos a diminuir a velocidade e deixamos o vídeo inteiro lento. Isso foi uma experiência muito bacana. A gente foi mostrar pro pessoal, e aí o pessoal falou, 'está muito rápido, né?' e quando aprendeu a desacelerar era a mesma coisa, tudo muito lento, o menino ia pular na água e nunca que caia dentro d'agua. (SICUPIRA, 2018)

A análise realizada manteve como foco todo o processo produtivo como uma condição para a existência do produto, lembrando que a TV Praça é uma iniciativa de audiovisual comunitário em que jovens produziam conteúdo e sentidos sobre o lugar em que moravam, com o conhecimento sobre as técnicas de produção de audiovisual muito básico, de forma amadora. As questões técnicas, estéticas e éticas que fazem parte do processo de aprendizagem produtiva e constituem os sentidos sobre o Vale do Jequitinhonha construídos pelos jovens. 


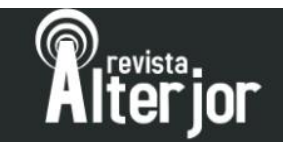

\section{Produção de sentidos sobre o Jequitinhonha pela TV Praça}

Um segundo momento da análise voltou-se para o produto audiovisual, qual seja, a materialidade discursiva expressa nas duas edições da TV Praça. As edições selecionadas para análise nesta pesquisa são compostas de dois quadros: Doc Jequi e Curta Legal. O primeiro é realizado inteiramente pelos jovens participantes do projeto, enquanto o segundo é uma seleção de vídeos curta-metragem de diversos autores, escolhidos para complementar a exibição. Naturalmente, o primeiro quadro acabou recebendo mais destaque na análise, devido ao seu aspecto mais autoral. ${ }^{9}$

\section{Sexta edição: II Fórum da mulher do Jequitinhonha}

A edição foi hospedada na plataforma youtube, no canal "Itaobim50anos", em 21 de julho de 2012, e soma o total de 41 minutos e 26 segundos. Esse tempo se divide entre vinhetas, cartelas de passagem ${ }^{10}$, uma cabeça ${ }^{11}$ contextualizando a edição, um encerramento seguindo os mesmos moldes, os créditos, um documentário que conta 23 minutos e 20 segundos e dois curtas-metragens de aproximadamente 5 e 8 minutos, respectivamente.

O quadro "Doc Jequi”, principal da TV Praça, exibe um documentário sobre o II Fórum da Mulher do Jequitinhonha. O evento foi realizado nos dias 24 e 25 de maio de 2012, reunindo mulheres de toda a mesorregião para debater temas como a participação e controle social, identidade das comunidades tradicionais, organização das mulheres e para criar um conselho da mulher nos municípios do Vale do Jequitinhonha.

As temáticas do evento atraíram um público muito específico: mulheres dos movimentos sociais da região. Podendo ser considerada uma condição de produção, a proposta do evento deixou fortes marcas no que se refere às figuras discursivas que compõem a produção.

\footnotetext{
9 As edições da Tv Praça estão disponíveis no canal do projeto Itaobim50anos, no Youtube e podem ser acessados no endereço eletrônico: www.youtube.com/Itaobim50anos.

${ }^{10}$ Mescla de imagens produzidas pelo grupo, utilizadas para transição de quadros.

${ }^{11}$ A Cabeça é a introdução de um tema dentro de um telejornal.
} 


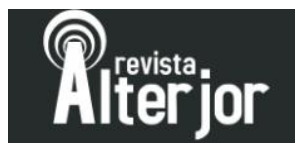

No início do documentário, uma cartela com o logotipo do evento aparece e os seguintes escritos: "Cinco mulheres. Cinco histórias de lugares e culturas diferentes, que se apresentam diante do espelho numa brincadeira que reflete identidades".

As mulheres entrevistadas para a produção do documentário refletem as condições de ocupação e desenvolvimento do Vale do Jequitinhonha, explicitadas no artigo. São elas: duas mulheres indígenas, uma quilombola, uma senhora negra e parteira e, por fim, uma mulher na faixa dos 60 anos e trabalhadora rural.

A dinâmica proposta foi a de enquadrar as entrevistadas em frente a um espelho para que elas se apresentassem por meio dele, compondo um plano subjetivo e trazendo autonomia para que essas pessoas falassem de si com maior liberdade, tirando-as da posição de passividade, já que não tinham a interferência de um entrevistador em vídeo. O plano subjetivo transforma a câmera nos olhos do personagem, fazendo com que a composição audiovisual seja algo que parte do seu ponto de vista.

Essas figuras quando se apresentam trazem para sua identidade a pobreza, o sofrimento e as dificuldades vividas ao longo da sua existência. Nesse sentido, é difícil entender até que ponto os estereótipos sobre a pobreza da região estão fixados nos imaginários dessas mulheres, ao ponto delas se construírem discursivamente por meio dessas más condições de vida, sem que tenha um contraponto. O fato é que essa construção contribui para reforçar o estereótipo que já circula tradicionalmente, quando essas mulheres se apresentam pela pobreza ou pela sua força. Ser uma pessoa "guerreira" nesse contexto significa também que você precisou batalhar para ter o básico e que nada foi conquistado de maneira fácil.

A edição em questão se resume aos quadros "Doc Jequi" e o quadro "curta legal”, que é composto por uma seleção de vídeos curta-metragem que compõe a edição da TV. A vinheta do "curta legal” é construída a partir de uma mescla de vídeos famosos, desde cenas de curtas-metragens, vídeo clipes e até filmes. A trilha sonora é formada pela música "The Golden Age" da banda "The Asteroids Galaxy Tour" e nas imagens é possível ver cenas das bandas como Blink 182, The Pretty Reckless, Michael Jackson, MGMT, The White Stripes e Paramore. Isso contrapõe outras trilhas sonoras utilizadas durante o restante da edição da TV e, principalmente, as trilhas sonoras do 


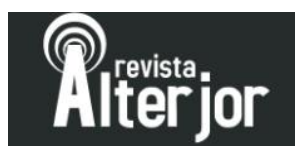

documentário apresentado. Uma vez que no "Doc Jequi", as músicas que apareciam eram cantigas tradicionais, mascadas pelo batuque dos tambores e remetendo as danças de roda da região. O pop e o pop rock internacional que se tornam referências no "Curta Legal" representam a forma com que os jovens produtores se veem no mundo, não sendo apenas os estereótipos impostos a eles desde o nascimento. Representam também o anseio de conhecer algo que não faz parte da sua realidade e que, até então, tinha sido visto apenas pelas telas dos seus computadores.

\section{Nona edição: Ponto dos chapas - Selva de pedra}

A segunda produção analisada neste trabalho é a nona edição da TV Praça, que tem o total de 19 minutos dividindo-se em: vinhetas, cartela de passagem, chamada inicial, encerramento, créditos, um documentário de aproximadamente nove minutos e dois curta- metragens, de dois e quatro minutos respectivamente.

O nome "chapa" é usado para denominar trabalhadores informais da cidade que descarregam caminhões de entrega nos arredores da rodovia BR-116. Na cidade de Itaobim, estabeleceram seu ponto entre a Avenida Rio Bahia e a própria rodovia, em uma região onde se localizam diversas lojas de material de construção, madeireiras e de peças automobilísticas; dessa forma, esses comerciantes geralmente pagam esses homens para ajudar a repor os estoques. No entanto, não há nenhuma formalidade ou garantias legais nesse trabalho e esse é um dos temas tratados no documentário.

Diferente do documentário que foi analisado anteriormente, neste não é cada “personagem" que se apresenta. Um deles aparece de pé e enquadrado em primeiro plano, um pouco à frente dos seus companheiros. É ele quem apresenta o grupo inteiro e a si mesmo. Além disso, essa figura que se coloca como principal responde a maioria das perguntas e de forma bastante direta, mostrando como os homens da região são acostumados a falar pouco ou que estão habituados a deixar que outra pessoa fale por eles.

A edição é finalizada com o quadro "curta legal”, em que dois vídeos rápidos são exibidos: o primeiro de apenas dois minutos é um curta da animação "Meu malvado favorito", com os Minions em tela em todo o momento; o segundo, também é uma 


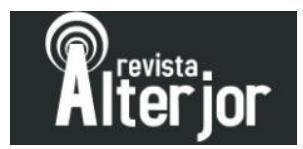

animação, chamada "One Man Band”, do estúdio Pixar. O vídeo de quatro minutos mostra dois homens que disputam a gorjeta de uma criança explorando suas habilidades musicais.

\subsection{As mulheres e os homens do Vale do Jequitinhonha}

Nas duas edições da TV Praça analisadas nesta pesquisa, foi possível observar que os documentários principais reproduzem e retratam a formação história e cultural do Vale do Jequitinhonha. Verificou-se que as condições de produção que permeiam os vídeos produzidos pelos jovens da TV Praça constroem os sentidos construídos sobre a região. Na sexta edição, a escolha das fontes a serem entrevistadas, isto é, das figuras discursivas que aparecem no documentário acontece durante um evento que promove o debate de políticas públicas para mulheres do Jequitinhonha, o que atrai um público seleto e militante nessa questão.

O documentário brinca com a identidade e apresenta as mulheres do Jequitinhonha como mulheres fortes, que, inseridas num contexto de marginalização e privação de direitos básicos, influenciado pela formação cultural do lugar, se viram na necessidade de lutar pelos seus ideais. A trabalhadora rural que em nenhum momento do vídeo fala seu nome coloca-se em segundo plano quando o assunto são as conquistas de direitos sociais que obteve por meio da sua militância. Direitos muitas vezes básicos, como o registro civil para mulheres idosas, motivo de maior orgulho para esta mulher.

As mulheres do Jequitinhonha também são alegria, medida pelo tamanho do sorriso de Geralda, a senhora negra e parteira que compõe o documentário, quando ela conta das mais de 700 crianças que vieram ao mundo com auxílio das suas mãos, e que não há alegria maior que ajudar colocar uma vida no mundo. A alegria sobrepõe a tristeza explicitada momentos antes da entrevista, quando ela revela a vida sofrida que teve, principalmente por não ter crescido em um ambiente familiar, sendo obrigada a trabalhar servindo os patrões da mãe.

Sanete, a mulher quilombola, carrega consigo a identidade da comunidade Mocó dos Pretos, mostrando que precisou de toda firmeza que carrega para se fazer ouvida. A mulher explicita também as relações de migração para cidades grandes, em busca de 


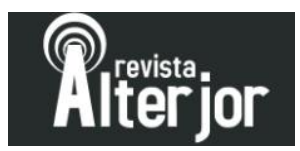

trabalho, algo que se torna necessidade para quem não encontra melhores oportunidades na própria terra. Já as mulheres indígenas mostram como a cultura se torna ponto crucial para a preservação da própria história e vivência.

A edição que trata dos chapas produz sentidos sobre os homens do lugar. Homens fortes, mas que precisam lidar com a falta de oportunidades de trabalho e se desdobram para conseguir sustento, apesar de algumas vezes se sentirem humilhados. $\mathrm{O}$ descontentamento aparece na fala de um deles, na mesma medida que não aparecem soluções: “é melhor do que roubar, né?". Essa frase é como se fizesse uma discussão parar e ele deixasse claro que a situação não é das melhores, mas que ele prefere isso a ser um criminoso.

Os documentários das duas exibições têm um ponto em comum: criam um discurso que relacionam o Vale à força. Ao contrário da mídia tradicional que coloca a pobreza como uma condição orgânica, o vídeo comunitário mostra, sim, a pobreza do Vale, mas revela também pessoas que lutam para que essa situação não fique estagnada.

A produção se insere em um projeto social ligado a uma universidade pública, por meio de um projeto de extensão; levando em consideração esse fator, junto ao potencial político do audiovisual comunitário, o discurso criado na tentativa de contrapor as mídias tradicionais acaba por vezes romantizando algumas questões sociais da região. Todo o processo de produção, principalmente do primeiro documentário analisado, produz sentidos relacionados à ideia de pessoas fortes e aguerridas, mas que, por vezes, não tem outras opções.

Já os curtas-metragens do quadro Curta Legal, que complementam as edições, mostram algo que não existe ali no Jequitinhonha. A vinheta, com bandas de pop rock estadunidenses e europeias, revela que os jovens que produzem conteúdo não se restringem ao consumo de cultura local ou que, apesar do contato com a cultura local, não a consome ativamente. Em um primeiro momento pode causar certo estranhamento, parecendo ser algo completamente desconexo dos documentários apresentados, mas que dizem muito sobre o olhar deles para o que vem de fora, para as referências que eles recebem nos produtos audiovisuais que costumam consumir. 


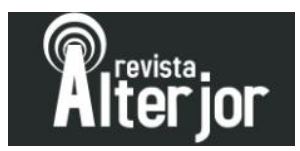

$\mathrm{Na}$ sexta edição, os documentários apresentam cidades que contrapõem os modos de vida narrados pelas mulheres entrevistadas. Uma delas até tentou se aventurar numa cidade grande, mas retornou ao Jequitinhonha para conseguir cuidar melhor da sua família. Já na nona edição, um curta-metragem sem fala quando os homens entrevistados, em maioria, falaram muito pouco ou de forma muito objetiva, com exceção de um deles que assume um papel de liderança. O silêncio ronda os homens da região, que se voltam ao trabalho e se acostumaram a falar pouco.

As categorias de análise técnicas, como enquadramento, planos, cenários e movimentos de câmera mostram o amadorismo da produção. Embora a nona edição apresente uma certa evolução técnica em relação à sexta, identificamos falhas técnicas como o microfone aparecendo em tela ou a dificuldade de enquadramento de uma das fontes. Embora esses erros aconteçam, a produção prefere utilizar esse tipo de imagem do que perder as falas dos entrevistados, dando mais importância para o conteúdo, para os modos de dizer das figuras discursivas presentes nas exibições, do que para questões de padrões estéticos.

\section{Considerações finais}

Diante da análise realizada, que teve como objetivo compreender como agentes produtores da TV Praça constroem sentidos sobre o Vale do Jequitinhonha, observa-se o quanto a complexa construção social do Vale do Jequitinhonha e as relações entre indígenas, negros e brancos reverberam até hoje. Seja nas condições precárias de algumas cidades, seja no traço identitário e artístico, que também é influenciado pela mídia carregada de estereótipos. Nesse sentido, o projeto da Assessoria de Comunicação Colaborativa tornou-se uma possibilidade para que, principalmente a juventude, se visse de outra maneira, produzindo sentidos sobre si e sobre o lugar de onde vêm a partir de novas perspectivas, de novos olhares.

A produção comunitária, seja o audiovisual ou as outras formas de expressão, torna-se, assim, importante para os grupos que encontram nela meios de manifestar seus desejos, suas formas de enxergarem o mundo e de se colocar nele. Além disso, esse tipo 


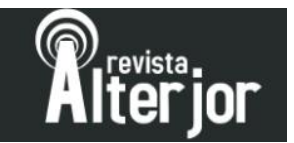

de produção permite o gozo do direito à comunicação, possibilitando o fortalecimento da democracia.

\section{Referências:}

ALVARENGA, Clarisse Castro. Refazendo caminhos do audiovisual comunitário contemporâneo. In: LEONEL, Juliana. MENDONÇA, Ricardo Fabrino. Audiovisual comunitário e educação: Histórias, processos e produtos. Belo Horizonte, Autêntica Editora, 2010 .

BENETTI, Marcia. Análise do Discurso em jornalismo: estudo de vozes e sentidos. In: LAGO, Cláudia; BENETTI, Márcia (org). Metodologia de Pesquisa em Jornalismo. Petópolis (RJ): Vozes, 2007.

CAMPOS, Israel. Entrevista concedida sobre a produção da TV Praça. 6 de setembro de 2018. Gravação em áudio, entrevistadora Elaíny Carmona Pereira. Disponível em: < https://repositorio.ufu.br/handle/123456789/24110> acesso: 21de nov. 2019

FURTADO, Júnia Ferreira. A história do Vale do Jequitinhonha. Cadernos do Leste, 77178. 2008. Disponível em: https://periodicos.ufmg.br/index.php/caderleste/article/view/13086 Acesso em: 21 de nov. 2019.

JARDIM, Maria Nelly Lages. O Vale e a vida: História do Jequitinhonha - Belo Horizonte: Armazém das ideias, 1998. 172p

KOSLINSKI, Aline Carla Salateski. Teorias da Comunicação Comunitária no Brasil. XVII Congresso de Ciências da Comunicação na Região Sul - Curitiba - PR. 2016. Disponível em: http://www.portalintercom.org.br/anais/sul2016/resumos/R50-0779-1.pdf. Acesso em: 21 de nov. 2019.

MENDONÇA, Ricardo Fabrino. Alguns argumentos em prol do audiovisual comunitário. In: LEONEL, Juliana. MENDONÇA, Ricardo Fabrino. Audiovisual comunitário e educação: Histórias, processos e produtos. Belo Horizonte, Autêntica Editora, 2010.

MOREIRA, Conrado Barbosa. Et all. Assessoria de Comunicação Colaborativa dos 200 anos da cidade de Jequitinhonha: perspectivas e experiências. XIX Prêmio Expocom 2012 - Exposição da Pesquisa Experimental em Comunicação. 2012. Disponível em: http://www.intercom.org.br/PAPERS/REGIONAIS/SUDESTE2012/expocom/EX33-0698-1.pdf Acesso em: 21 de nov. 2019.

NASCIMENTO, Elaine Cordeiro do. Vale do Jequitinhonha: Entre a carência social e a riqueza cultural. Contemporâneos: Revista de Artes e Humanidades $N^{\circ} 4$ - Maio/Outubro 2009. Disponível em: http://www.revistacontemporaneos.com.br/n4/pdf/jequiti.pdf. Acesso em: 21 de nov. 2019.

ORLANDI, Eni Puccinelli. Análise do discurso: Princípios e procedimentos. Campinas, SP: Pontes, $6^{\text {a }}$ edição. 2005.

Revista ALTERJOR

Grupo de Estudos Alterjor:Jornalismo Popular e Alternativo (ECA-USP)

Ano 10 Volume 02 Edição $22 \quad$ Juho- Dezembro de 2020

Avenida Professor Lúcio Martins Rodrig̉ues, 443, Cidade Universitária, São Paulo, CEP: 05508-020 


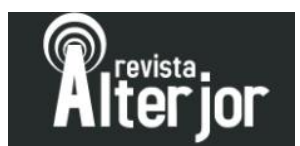

PARANHOS, Caio Ribeiro. A representação do Vale do Jequitinhonha no jornal Estado de Minas. Belo Horizonte. 2015.

PERUZZO, Cicilia M. Krohling. Aproximações entre a comunicação popular e comunitária e a imprensa alternativa no Brasil na era do ciberespaço. Revista Galáxia, São Paulo, n. 17, p. 131-146, jun. 2009

PERUZZO, Cicilia M. Krohling. Revisitando os Conceitos de Comunicação Popular, Alternativa e Comunitária. XXIX Congresso Brasileiro de Ciências da Comunicação. Brasília. 2006.

PERUZZO, Cicilia M. Krohling. TV comunitária no Brasil: aspectos históricos. RBC: / TV e cidadania. Porto Alegre: Rede Brasil de Comunicação Cidadã, 2002, v. p. Disponível em: 1- 22 http://www.bocc.ubi.pt/pag/peruzzo-cicilia-tv-comunitaria.pdf Acesso em: 10 de nov. 2018.

SICUPIRA, Anna Beatriz. Entrevista concedida sobre a produção da TV Praça. 4 de setembro de 2018. Gravação em áudio, entrevistadora Elaíny Carmona Pereira. Disponível em: < https://repositorio.ufu.br/handle/123456789/24110> acesso: 21 de nov. 2019

SOARES, Geralda Chaves. Vale do Jequitinhonha: um vale de muitas culturas. Cadernos de História, Belo Horizonte v. 5 n. 6 p. 17- 22. 2000. Disponível em: http://periodicos.pucminas.br/index.php/cadernoshistoria/article/view/1701 Acesso em: 21 de nov. 2019.

SOUZA, João Valdir Alves de. Fontes para uma reflexão sobre a história do Vale do Jequitinhonha. UNIMONTES CIENTÍFICA. Montes Claros: Universidade Estadual de Montes Claros. v.5, n.2, jul./dez. 2003

TV PRAÇA - ITAOBIM. Nona edição. Assessoria de Comunicação Colaborativa Itaobim 50 anos. Publicado em 20 de setembro de 2012. Suporte digital. Disponível em: https://www.youtube.com/watch?v=ypiElmRovgc\&t=88s Acesso em: 21 de nov. 2019.

TV PRAÇA - ITAOBIM. Sexta edição. Assessoria de Comunicação Colaborativa Itaobim 50 anos. Publicado em 21 de julho de 2012. Suporte digital. Disponível em: https://www.youtube.com/watch?v=1wl6paDP7c0\&t=578s Acesso em: 21 de nov. 2019.

VERÓN, Eliseo. Fragmentos de um tecido. Tradução: Vanise Dresh. Editora Unisinos. 2004.

Revista ALTERJOR

Grupo de Estudos Alterjor:Jornalismo Popular e Alternativo (ECA-USP)

Ano 10 Volume 02 Edição $22 \quad$ Juho- Dezembro de 2020

Avenida Professor Lúcio Martins Rodrig̉ues, 443, Cidade Universitária, São Paulo, CEP: 05508-020 